\title{
Associations between paratuberculosis status and milk production traits in Holstein cattle under consideration of interaction effects between test result and farm and lactation number
}

\author{
Julia Küpper ${ }^{1}$, Horst Brandt ${ }^{1}$, Karsten Donat ${ }^{2}$ and Georg Erhardt ${ }^{1}$ \\ 'Institut für Tierzucht und Haustiergenetik, Justus-Liebig-Universität, Gießen, Germany, ${ }^{2}$ Thüringer Tierseuchenkasse, \\ Jena, Germany
}

\begin{abstract}
One of the most important factors for economic losses as result of infection with Mycobacterium avium ssp. paratuberculosis (MAP) is the decrease in milk yield. Different phenotyping methods for MAP lead to an inconsistent impact of MAP infection on milk parameters. It was the aim of the study to analyse the effect of the MAP status on milk yield, milk fat and milk protein (in kilograms), as well as on the calving interval and milk kilograms per day of life in German Holstein cattle. A dataset of 9367 faecal culture tested animals from 14 farms in Thuringia (Germany) were available. The MAP status of the animals affected milk yield and the milk parameters. Beside the effects of farm, lactation number and MAP status, the interaction between MAP status and farm on the milk parameters was significant. The latter result is a possible explanation for the inconsistent results from recent studies. For milk $\mathrm{kg}$ per day of life, the interaction between lactation number and MAP status also showed significance.
\end{abstract}

Keywords: Mycobacterium avium ssp. paratuberculosis, milk parameters, faecal culture, MAP

Abbreviations: MAP: Mycobacterium avium ssp. paratuberculosis, ParaTB: Paratuberculosis

Archiv Tierzucht 56 (2013) 94, 924-933

doi: 10.7482/0003-9438-56-094

Corresponding author:

Georg Erhardt; email: georg.erhardt@agrar.uni-giessen.de

Institut für Tierzucht und Haustiergenetik, Justus-Liebig-Universität, Ludwigstraße 21b, 35390 Giessen, Gemany

() 2013 by the authors; licensee Leibniz Institute for Farm Animal Biology (FBN), Dummerstorf, Germany.

This is an Open Access article distributed under the terms and conditions of the Creative Commons Attribution 3.0 License

(http://creativecommons.org/licenses/by/3.0/).
Received: 2 August 2013

Accepted: 5 November 2013

Online: 6 November 2013 


\section{Introduction}

Paratuberculosis (ParaTB), also known as Johne's disease, caused by the facultative pathogen Mycobacterium avium ssp. paratuberculosis (MAP) is a chronic disease of ruminants. The infection of cows with MAP takes place as calves and the infection of a mature animal is rare (Windsor \& Whittington 2009). Whitlock \& Buergelt (1996) classified the status of infection with MAP into four stages: first as »silent « infection, second as subclinical disease, third as clinical disease and fourth as advanced clinical disease. In the first stage animals up to two years of age are infected with MAP. In this early phase of disease there is no apparent evidence of infection and the detection of MAP is not possible neither by ELISA nor by faecal culture. In the subclinical stage animals show no typical signs of ParaTB but can be susceptible to other diseases. These cows may have detectable antibodies and infection in a small number of animals may be detected by faecal culture, whereas the infection is undetectable in the majority of animals in this phase. The third stage is characterized by a long incubation time (2-10 years). In this stage typical clinical signs like diarrhoea and weight loss appear. Most animals are culled before stage four, which is characterized by increasingly lethargy, emaciation and profuse diarrhoea up to the point of death. As a result of the infection reduced fertility and a reduced milk production in dairy cattle are observed (McKenna et al. 2006). Faecal cultures as well as available ELISA tests in serum and milk have a low sensitivity with $60 \%$ and respectively $30 \%$ (Collins et al. 2006). This leads to a high amount of undetected infected cows.

Recent prevalence studies reviewed by Tiwari et al. (2006) mention herd prevalence rates for Canadian regions between $33.3 \%$ and $74.0 \%$, for US states between $41 \%$ and $66 \%$ and for European countries between $7 \%$ for Austria and $54 \%$ for the Netherlands. The apparent prevalence rates varied because of the different tests and designs which are used in these studies (Nielsen \& Toft 2008).

Many studies deal with the resulting economic losses of the disease. Factors like permanent culling to decrease the risk of infection, reduced fertility and higher feed intake are involved in the amount of economic losses (Raizman et al. 2009). Estimated losses for the US dairy industry were around US\$ 200 to US\$ 250 million annually (Ott et al. 1999). Chi et al. (2002) estimated total costs for an average infected 50 cow herd of 2472 US\$/year. One of the important factors for economic losses is the decrease in milk yield. The deficit of milk income in the current lactation is estimated of $276 \$$ for faecal positive cows vs. negative ones (Raizman et al. 2009). More and more studies deal with the context of lactation performances and ParaTB status in cows (Lombard et al. 2005, Gonda et al. 2007, Raizman et al. 2007, 2009, Sorge et al. 2010). In all studies the milk yield of MAP positive cows was reduced, but the amount differs between $212 \mathrm{~kg}$ (Tiwari et al. 2007) and $1803 \mathrm{~kg}$ (Raizman et al. 2009) per 305day lactation. In the majority of these studies the ParaTB status of the animals is detected either by faecal culture (Raizman et al. 2007, 2009) or by ELISA (Nielsen et al. 2002, Sorge et al. 2011) or with both (Gonda et al. 2007).

The effect of the MAP infection on milk protein and milk fat content is unclear. Some studies found a decrease in milk-fat and -protein content in infected animals (Benedictus et al. 1987) whereas other studies found no associations (Nordlund et al. 1996, Lombard et al. 2005). Also results about other performance traits, such as reproduction or somatic cell 
score are inconsistent. One main reason for the inconsistency of results from the literature could be the fact that different definitions of MAP positive and MAP negative animals are used and the fact that in some studies negative and positive animals included are not from the same farm.

Literature shows different definitions of MAP positive animals based on different tests for MAP as well as the resulting differences in milk production traits between MAP positive and MAP negative animals. Thus, this study aims to further clarify the impact on MAP on production traits by analysing the interaction between farm effects and the MAP status of animals.

So far the latter aspect has not been discussed in published literature but may be a possible explanation for the varying results.

\section{Material and methods}

9367 German Holstein cows from 14 farms in Thuringia all routinely tested for MAP by faecal culture (Donat et al. 2012) were analysed for the study. This data represents nearly all female animals older than 24 month between 2007 and 2009 of these farms. For all animals full pedigree information and milk recording traits were available. All herds included in this study joined the »Paratuberculosis Control Program in Thuringian Cattle Herds« which is organized by the Thuringian Animal Health Service. The program includes, among other measures, annual whole herd screenings (cows $>24$ month) for MAP by faecal culture. If an animal was detected as MAP positive, it was not retested the next year and culling is recommended as outlined by Sweeney et al. (2012).

The association between the paratuberculosis status and the different milk performance traits in the actual lactation in which the cow was tested (milk kilograms, fat in kg, as well as protein in kg, all parameters for 305-days) was analysed using the software system SAS (SAS 9.1, SAS Institute Inc., Cary, USA). For the GLM procedure the following linear model was used:

$$
Y_{i j k l}=\mu+f_{i}+l_{j}+t_{k}+(f \times t)_{i k}+(l \times t)_{j k}+e_{i j k l}
$$

where $Y_{i j k l}$ is the phenotypic observation of cow $i j k l, \mu$ is the constant mean, $f_{i}$ is the fixed effect of farm $i(i=1-14), l_{j}$ is the fixed effect of lactation number $j(j=1,2,3, \geq 4), t_{k}$ is the fixed effect of test result $k$ ( $k=$ positive or negative), $(f \times t)_{i k}$ is the fixed interaction of farm by test result, $(/ \times t)_{j k}$ is the fixed interaction of lactation number by test result and $e_{i j k l}$ is the random residual effect.

Additionally, we analysed the differences between positive and negative tested animals in milk kg per day of life and calving interval in days using all available lactations. In total for the tested cows data of 21887 lactations are available.

For these traits in the model the effects of farm, lactation number, faecal test result and the interaction between farm and faecal test result as well as the interaction between lactation number and faecal test result were included as fixed effects and the cow as random effect. For the analysis of the calving interval we excluded the first lactations, so 12933 observations remained for the analysis. 


\section{Results}

MAP tests - milk parameters

From the 9367 animals 1136 cows are positive and 8231 animals are negative for MAP tested by faecal culture. The prevalence in the herds ranges between $3.2 \%$ and $64.4 \%$. Eight farms shows prevalence rates $<10 \%$, three farms between $10 \%$ and $20 \%$, two farms between $20 \%$ and $30 \%$ and one farm with $64.4 \%$. Table 1 shows the animals with full pedigree information and milk recording data grouped by number of lactation and the test results.

The average milk yield (305-days) over all farms is $8919 \mathrm{~kg}$ with $4.03 \%$ fat and $3.36 \%$ protein. The farm with the lowest milk yield has an average of $8138 \mathrm{~kg}$ and the farm with the highest milk yield of $10428 \mathrm{~kg}$. As shown in Table 2 the differences for the 305-day milk, fat and protein yield in $\mathrm{kg}$ between the positive and the negative animals are significant. The table also shows that the parameters »farm « and »lactation number« have a significant influence on the milk parameters.

Table 1

Distribution of animals per number of lactation, tested for MAP by faecal culture

\begin{tabular}{lcc}
\hline Lactation number & MAP test result & Faecal culture (total 9367) \\
\hline 1 & negative & 3482 \\
& positive & 411 \\
& negative & 2322 \\
3 & positive & 343 \\
& negative & 1235 \\
$\geq 4$ & positive & 207 \\
& negative & 1192 \\
Total & positive & 175 \\
& negative & 8231 \\
& positive & 1136 \\
\hline
\end{tabular}

Table 2

Significances of the influence of MAP status, farm, lactation number and interaction effects on milk in $\mathrm{kg}$, fat in $\mathrm{kg}$ and protein in $\mathrm{kg}$ of the 305-day lactation and milk per day of life and calving interval

\begin{tabular}{lccccc}
\hline Parameter & Milk & Fat & Protein & Milk/day of life & Calving interval \\
\hline Farm & $* * *$ & $* * *$ & $* * *$ & $* * *$ & $* * *$ \\
Lactation number & $* * *$ & $* * *$ & $* * *$ & $* * *$ & $*$ n* \\
Faecal culture & $* *$ & $* * *$ & $* * *$ & $* * *$ & $\mathrm{~ns}$ \\
Farm $\times$ faecal culture & $* * *$ & $* *$ & $* * *$ & $* * *$ & $\mathrm{~ns}$ \\
Lactation number $\times$ faecal culture & $* *$ & $* *$ & $* * *$ & $* * *$ & $\mathrm{~ns}$ \\
\hline
\end{tabular}

${ }^{*} P \leq 0.05,{ }^{* *} P \leq 0.01,{ }^{* * *} P \leq 0.001$, ns: not significant

Animals which were tested positive for MAP have a lower 305-day milk yield in kg (Figure 1). The average difference was $225 \mathrm{~kg}$ milk for 305 -day milk yield. Also the fat and protein yields in $\mathrm{kg}$ for the 305-day lactation (Figure 1) were higher in negative animals than in positive ones. 

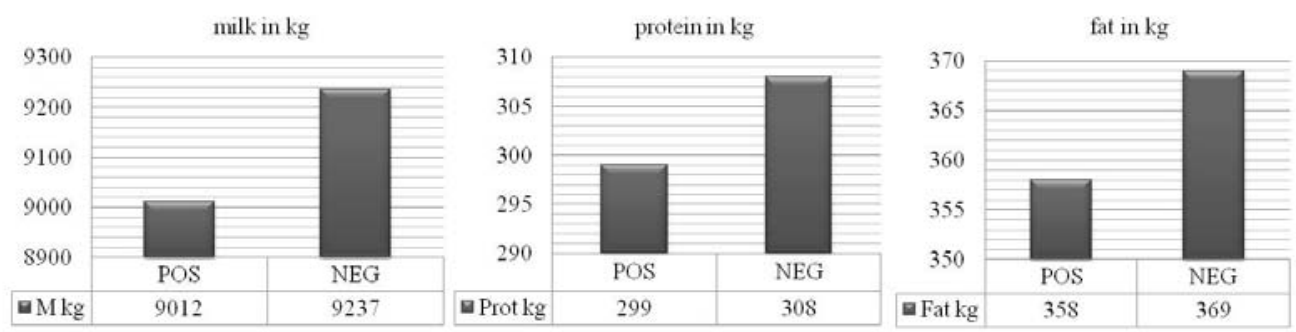

Figure 1

LS means for positive and negative faecal culture tested cows $(n=9367)$ for the average 305-day milk, protein and fat in $\mathrm{kg}$

\section{Calving interval}

The effects of farm and lactation number show a significant influence on the calving interval (Table 2). The negative tested animals show an insignificant two day shorter calving interval in comparison to the positive tested animals. Neither the interactions between faecal test result and farm nor lactation number, respectively, show a significant influence on calving interval.

\section{Milk kg per day of life}

The fixed effects farm, number of lactation and faecal culture test results, as well as the interaction between faecal culture test result and farm and lactation number respectively show a high significant influence on the parameter milk kg per day of life (Table 2). Figure 2 shows the influence of lactation number on milk $\mathrm{kg}$ per day of life for positive and negative tested animals within number of lactation. With increasing lactation number an increasing difference between positive and negative tested animals is observed ranging from 0.02 to $0.81 \mathrm{~kg}$ per day of life.

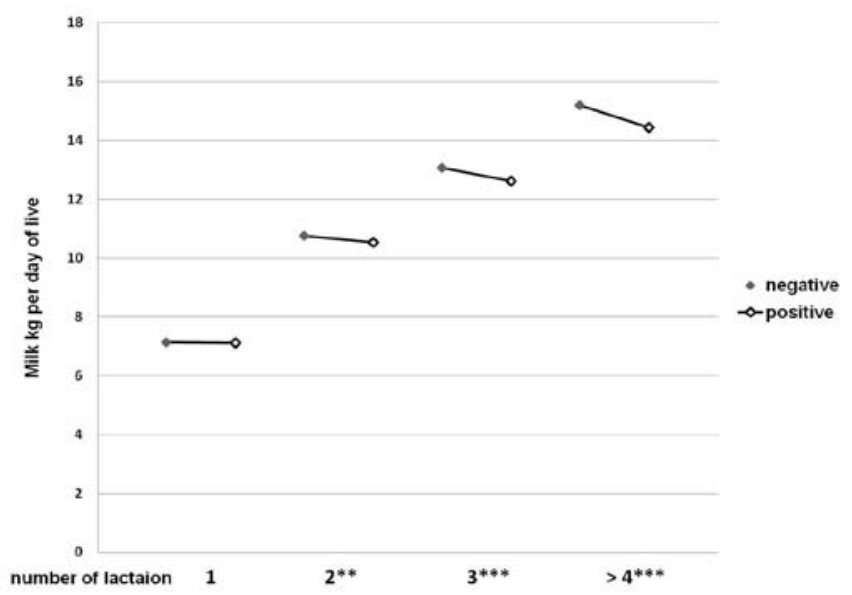

Figure 2

LS means for the milk per day of life in $\mathrm{kg}$ and number of lactation in faecal culture tested animals $\left({ }^{*} P \leq 0.05\right.$, $\left.{ }^{* *} P \leq 0.01,{ }^{* * *} P \leq 0.001\right)$ 


\section{Interaction between farm and faecal culture test result}

The significant interaction between farm and faecal culture test results (Table 2) for 305-day milk yield is shown in Figure 3. In the majority of farms the negative tested animals show higher milk yield than the positive tested animals. In four of the 14 farms this difference is significant. The differences range between 220 and $904 \mathrm{~kg}$ of milk. In three of the $14 \mathrm{farms}$ the positive tested cows show a higher 305-day milk yield ranging between 166 and $445 \mathrm{~kg}$. In two farms the difference between positive and negative tested cows is very small.

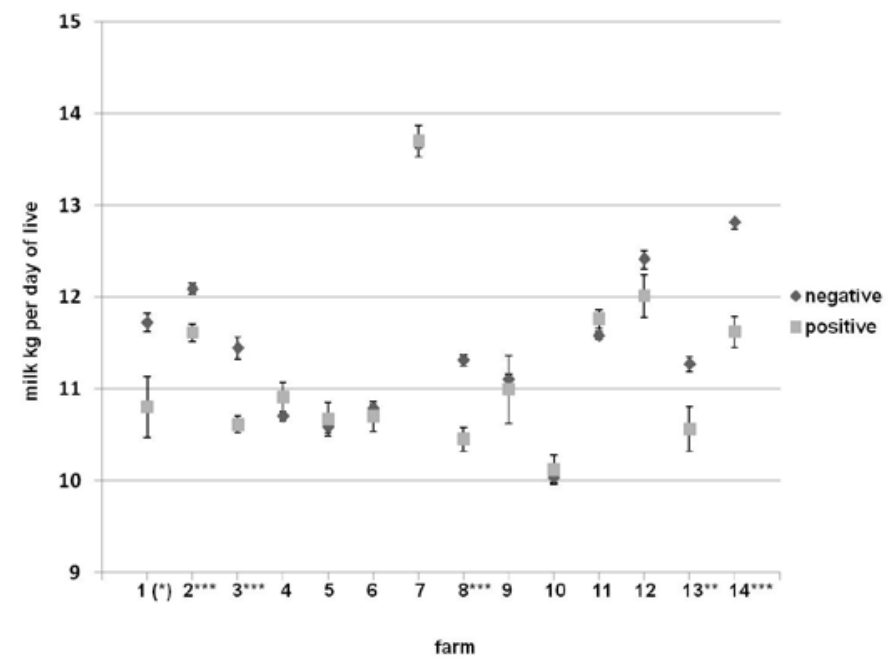

Figure 3

LS means for the average 305-day milk yield in $\mathrm{kg}$ for the interaction between farm and paratuberculosis status tested by faecal culture $\left({ }^{*} P \leq 0.05,{ }^{*} P \leq 0.01\right.$, $\left.{ }^{* * *} P \leq 0.001\right)$

As consequence of the interaction component for milk lactation yield and the differences in calving interval as described before a highly significant interaction between farm and test result is also observed for $\mathrm{kg}$ of milk per day of life (Figure 4). The lower yield of milk per day of life for the positive tested animals is caused by milk reduction, higher first calving age and longer calving interval as shown in farms 8 and 13 especially. In contrast to that in farm 3 the lower kg of milk per day of life for the positive tested animals is only an effect of a very high milk reduction of $904 \mathrm{~kg}$ in positive tested animals.

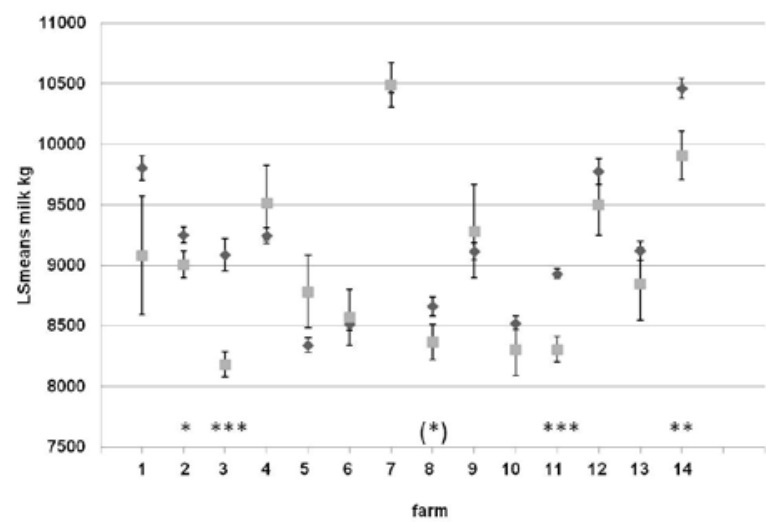




\section{Discussion}

The results of the present study confirms the hypothesis that MAP positive animals show a decrease in the milk yield compared to negative tested animals. The reduction in milk production in MAP positive animals is on average $225 \mathrm{~kg}( \pm 375 \mathrm{~kg})$ and is equivalent to a milk reduction of $2.4 \%$. This confirms the results reported by Hendrick et al. (2005) with losses in milk between $2 \%$ and $6 \%$ depending on the diagnostic test used.

In general, the results about the decrease in milk kg in positive animals from the literature are heterogeneous and range between $206 \mathrm{~kg}$ and $1364 \mathrm{~kg}$ per lactation (Shook et al. 2012, Raizman et al. 2009, Richardson \& More 2009, Sorge et al. 2011, Tiwari et al. 2007). One reason for this wide range of differences between MAP positive and negative tested animals could be the difference in the tests used or in the definition of MAP status itself. Some studies used a single test to classify the MAP status of animals while in other studies multiple test results for classification were combined to define positive tested animals.

A second major reason for the differing results is probably the highly significant interaction between farm and test results shown in our study (Figure 3 and Figure 4). In some farms positively tested animals do not show any decrease in milk production. Looking at the results shown in Figure 3 it can be recognized that the level of milk production in the farms in our study does not have an influence on the difference between positive and negative tested cows. In both farms, 7 and 14, the average is higher than $10000 \mathrm{~kg}$ of milk per lactation, but while in farm 7 no difference between positive and negative animals is observed, this difference is significant with $554 \mathrm{~kg}$ in farm 14 . The same differing results are observed for farms 3, 6 and 10 with an average of milk kg per lactation of around $8500 \mathrm{~kg}$.

There is more a tendency that the difference between positive and negative tested cows in milk production traits is depending on the herd prevalence. We could demonstrate that a lower herd prevalence level leads to lower differences by comparing the herd prevalence of the four farms with the significant lower milk production for positive tested animals with the prevalence of the other farms. The farms with the significant differences show prevalence rates between $12.5 \%$ and $64 \%$, while the others have prevalence rates below $12 \%$ and the farms with nearly equal milk production of positive and negative tested animals have the lowest prevalence rates. Beside this prevalence effect, the time of infection probably has an influence on milk production. The above mentioned four farms with the highest prevalence rates also have the highest percentage of cows tested positive already in the first lactation and in these farms in later lactations no higher prevalence rates are observed, as described by Küpper et al. (2012).

Gonda et al. (2007) also reported a decrease in fat $\mathrm{kg}(10-23 \mathrm{~kg})$ and protein kg (8.3-18 kg). In the present study we could also observe a significant decrease in fat $\mathrm{kg}$ and in protein yield. The analysis of the fat- and protein percentages offers no differences between positive and negative tested animals. So the significant reduction in fat- and protein yield would be a result of the milk yield decrease, whereas the milk composition in total will be unchanged.

As measurement of reproductive efficiency often the calving interval or the days open are used. The results of different studies are conflicting. Raizmann et al. (2009) found no significant difference between positive and negative tested cows. Johnson-Ifearulundu et al. (2000) reported a significant increase in days open in ELISA positive cows, but no 
significant differences in faecal tested cows. Lombard et al. (2005) reported that cows with strong positive ELISA test results showed fewer days open than cows with negative ELISA test results. The study of Ansari-Lari et al. (2012) showed nearly significance in calving interval between positive and negative tested herds. In our study we are in agreement with results of the latter study, observing a nearly significant influence $(P=0.051)$ of the MAP test result on the calving interval. As shown already for milk production traits, the results for calving interval are probably also dependent on the test used and furthermore influenced by a significant interaction between farm and MAP status. Our results show that this interaction is significant also for first calving age $(P \leq 0.05)$ and although not significant for calving interval, differences between 16 days of longer calving interval for positive tested animals to 31 days shorter calving interval for the positive animals are observed within farms.

Taking into account all lactations of tested cows an increasing effect with higher lactation numbers for kg of milk per day of life is observed. Within the first lactation there is no difference between positive and negative tested animals while in later lactations this difference is increased and highly significant (Figure 2). This effect could be a cumulative effect of the reduced milk production per lactation of MAP infected animals and the increased calving interval of the positive tested cows versus negative tested ones.

Other studies used as reference negative tested in certified-free herds (Beaudeau et al. 2007) which would definitely have an influence on the results in case of significant interaction effects between farm and MAP status as shown in our study.

Because of a lack of knowledge regarding all costs connected with MAP (e.g. culling costs, costs regarding food intake of positive and negative tested animals) we could not account all costs of MAP infection. However, based on the fact that the average milk price in Germany varied between 31.56 cents and 34.77 cents per litre in the last years the annual losses of income are between $71 €( \pm 118 €)$ up to $78 €( \pm 130 €)$ per cow as result of the deficit in milk yield.

In conclusion, the present results show that milk yield and milk parameters in dairy cows are affected by the MAP status of the animals and a high significant interaction between farm and MAP status exists. Results of the interaction between farm and MAP infection status show that these differences between positive and negative tested cows in milk production are probably dependent on herd prevalence but not on average milk yield of farm.

\section{Acknowledgements}

The authors would like to thanks the herd book breeders from Thuringia for participating in the voluntary program and for providing the data and samples.

\section{References}

Ansari-Lari M, Haghkhah M, Mahmoodi F (2012) Association of Mycobacterium avium subspecies paratuberculosis infection with milk production and calving interval in Iranian Holsteins. Trop Anim Health Prod 44, 1111-1116

Benedictus G, Dijkhuizen AA, Stelwagen J (1987) Economic losses due to paratuberculosis in dairy cattle. Vet $\operatorname{Rec} 121,142-146$ 
Beaudeau F, Belliard M, Joly A, Seegers H (2007) Reduction in milk yield associated with Mycobacterium avium subspecies paratuberculosis (Map) infection in dairy cows. Vet Res 38, 625-634

Chi J, VanLeeuwen JA, Weersink A, Keefe GP (2002) Direct production losses and treatment costs from bovine viral diarrhoea virus, bovine leukosis virus, Mycobacterium avium subspecies paratuberculosis, and Neospora caninum. Prev Vet Med 55, 137-153

Collins MT, Gardner IA, Garry FB, Roussel AJ, Wells SJ (2006) Consensus recommendations on diagnostic testing for the detection of paratuberculosis in cattle in the United States. J Am Vet Med Assoc 229, 1912-1919

Donat K, Schau U, Soschinka A, Köhler H (2012) [Herd prevalence studies of Mycobacterium avium ssp. paratuberculosis (MAP) in cattle using serological tests: opportunities, limitations and costs]. Berl Münch Tierärztl Wochenschr 125, 361-370 [in German]

Gonda MG, Kirkpatrick BW, Shook GE, Collins MT (2007) Identification of a QTL on BTA20 affecting susceptibility to Mycobacterium avium ssp. paratuberculosis infection in US Holsteins. Anim Genet 38, 389-396

Hendrick SH, Kelton DF, Leslie KE, Lissemore KD, Archambault M, Duffield TF (2005) Effect of paratuberculosis on culling, milk production, and milk quality in dairy herds. J Am Vet Med Assoc 227, 1302-1308

Johnson-Ifearulundu YJ, Kaneene JB, Sprecher DJ, Gardiner JC, Lloyd JW (2000) The effect of subclinical Mycobacterium paratuberculosis infection on days open in Michigan, USA, dairy cows. Prev Vet Med 46, 171-181

Küpper J, Brandt H, Donat K, Erhardt G (2012) Heritability estimates for Mycobacterium avium subspecies paratuberculosis status of German Holstein cows tested by fecal culture. J Dairy Sci 95, 2734-2739

Lombard JE, Garry FB, McCluskey BJ, Wagner BA (2005) Risk of removal and effects on milk production associated with paratuberculosis status in dairy cows. J Am Vet Med Assoc 227, 1975-1981

McKenna SLB, Keefe GP, Tiwari A, VanLeeuwen J, Barkema HW (2006) Johne's disease in Canada Part II: Disease impacts, risk factors, and control programs for dairy producers. Can Vet J 47, 1089-1099

Nielsen SS, Enevoldsen C, Gröhn YT (2002) The Mycobacterium avium subsp. paratuberculosis ELISA response by parity and stage of lactation. Prev Vet Med 54, 1-10

Nielsen SS, Toft N (2008) Ante mortem diagnosis of paratuberculosis: A review of accuracies of ELISA, interferon- $\gamma$ assay and faecal culture techniques. Vet Microbiol 129, 217-235

Nordlund KV, Goodger WJ, Pelletier J, Collins MT (1996) Associations between subclinical paratuberculosis and milk production, milk components, and somatic cell counts in dairy herds. J Am Vet Med Assoc 208, 18721876

Ott SL, Wells SJ, Wagner BA (1999) Herd-level economic losses associated with Johne's disease on US dairy operations. Prev Vet Med 40, 179-192

Raizman EA, Fetrow J, Wells SJ, Godden SM, Oakes MJ, Vazquez G (2007) The association between Mycobacterium avium subsp. paratuberculosis fecal shedding or clinical Johne's disease and lactation performance on two Minnesota, USA dairy farms. Prev Vet Med 78, 179-195

ORichardson EKB, More SJ (2009) Direct and indirect effects of Johne's disease on farm and animal productivity in an Irish dairy herd. Ir Vet J 62, 526-532

Shook GE, Chaffer M, Wu XL, Ezra E (2012) Genetic parameters for paratuberculosis infection and effect of infection on production traits in Israeli Holsteins. Anim Genet 43 (Suppl.), 56-64

Sorge U, Kelton D, Lissemore K, Godkin A, Hendrick S, Wells S (2010) Attitudes of Canadian dairy farmers toward a voluntary Johne's disease control program. J Dairy Sci 93, 1491-1499

Sorge US, Lissemore K, Godkin A, Hendrick S, Wells S, Kelton D (2011) Association between paratuberculosis milk ELISA results, milk production, and breed in Canadian dairy cows. J Dairy Sci 94, 754-761

Sweeney RW, Collins MT, Koets AP, McGuirk SM, Roussel AJ (2012) Paratuberculosis (Johne's Disease) in Cattle and Other Susceptible Species. J Vet Intern Med 26, 1239-1250

Tiwari A, VanLeeuwen JA, McKenna SLB, Keefe GP, Barkema HW (2006) Johne's disease in Canada: Part I: Clinical symptoms, pathophysiology, diagnosis, and prevalence in dairy herds. Can Vet J 47, 874-882 
Tiwari A, VanLeeuwen JA, Dohoo IR, Keefe GP, Haddad JP, Tremblay R, Scott HM, Whiting T (2007) Production Effects of Pathogens Causing Bovine Leukosis, Bovine Viral Diarrhea, Paratuberculosis, and Neosporosis. J Dairy Sci 90, 659-669

Whitlock RH, Buergelt C (1996) Preclinical and clinical manifestations of paratuberculosis (including pathology). Vet Clin North Am Food Anim Pract 12, 345-356

Windsor PA, Whittington RJ (2009) Evidence for age susceptibility of cattle to Johne's disease. Vet J 184, 37-44 